\title{
Tourist Intercultural Competence: A Multidimensional Measurement and its Impact on Tourist Active Participation and Memorable Cultural Experiences
}

\begin{abstract}
Cultural tourism has received increasing attention. Tourists' intercultural competence represents the abilities to appropriately and efficiently interact with people across different cultures, helping tourists attain developing positive cultural exchange experiences. By adopting both qualitative and quantitative approaches, a multi-dimensional measurement of tourists' intercultural competence was developed and validated in this study. Four factors of tourists' intercultural competence were identified: intercultural responsibility, understanding, appreciation, and action. Furthermore, this study examined the association between tourists' intercultural competence and memorable cultural experience and determined the mediating effects of tourists' active participation. This study contributes to the cultural tourism literature by proposing a measurement of tourists' intercultural competences and by establishing a framework illustrating how cultural tourists interact with different cultures, thus attaining memorable cultural experiences. Managerial implications for destination marketing and tourist management are discussed herein.
\end{abstract}

Keywords: intercultural competence, cultural tourism, tourist participation, memorable experience, scale development. 


\section{Introduction}

Cultural tourism has received increasing interest in practice and academia (Gnoth and Zins 2013; World Tourism Organization [UNWTO] 2018). Confirming the importance of cultural tourism, a survey in 2016 has revealed that $89 \%$ of national tourism administrations considered cultural tourism as a part of their tourism policy. Moreover, regarding the size of the cultural tourism market, cultural tourism constituted over $39 \%$ of all international tourism arrivals, with 4\% growth per year (UNWTO 2018). With continued growth, cultural tourism has shifted from a niche market with relatively well-educated and high-income tourists to a mass market open to a wider range of tourists, creating new challenges for destinations (Richards 2018). Tourism development has facilitated cultural exchange and increased economic benefits (Richards 2018). However, it has negatively affected local residents and communities. With destinations absorbing an increasing number of tourists, sociocultural sustainability and longer-term viability have become the main concerns of destination managers (Zhang et al. 2017).

Cultural tourists are motivated by experiencing and learning about various cultures (Boyd 2002). They play a key role in rewarding experience and cultural understanding (Su et al. 2016b), becoming the key actors involved in cultural contacts. Moreover, cultural tourists are not only involved in pursuing cultural experiences, but also undertaking the responsibility and obligation to preserve local culture and society (Featherstone, 2002). Drawing on crosscultural competences, cultural conflicts or mutual understanding can be stimulated (Reisinger 2009; Tsaur, Yen, and Teng 2018; Ye, Zhang, and Yuen 2013). Conflicts may arise among stakeholders when tourists and hosts share different perceptions and goals regarding tourism activities, such as benefits, personal interests, quality, or cost perceptions (Tsaur, Yen, and Teng 2018).

Therefore, understanding cultural tourists to effectively manage a cultural tourism site is 
essential (Chen and Rahman 2018). Tourist behavior management and education are highlighted in cultural tourism research. Cultural tourists require a certain level of intercultural competence while consuming cultural materials; thus, "intercultural competence" has become an emerging focus of tourism research (Richards 2018). Intercultural competence refers to "the skills and abilities that an individual needs in order to interact appropriately and efficiently with persons from a different culture" (Scherle and Nonnenmann 2008). Concepts related to intercultural competence applied in tourism literature include the following: intercultural sensitivity (Donohoe 2011; Kirillova, Lehto, and Cai 2015); intercultural understanding (Kirillova, Lehto, and Cai 2015; Raymond and Hall 2008); tourists' appreciation (McIntosh 2004); cultural contact (Gnoth and Zins 2013); cultural mobility (Mueller, Peters, and Weiermair 2009); tourists' predisposition (Nowaczek and Smale 2010); and cosmopolitanism (Molz 2006; Swain 2009). These constructs have been respectively applied in different tourism contexts, such as cultural tourism, ecotourism, international tourism, and volunteer tourism. The domain of tourists' intercultural competence was used in different contexts, which remains overlapping and vague.

The following concerns have been raised in the literature on cultural tourism and tourists' intercultural competences. First, cultural tourism has become a major market in the tourism industry. Studies have focused on residents' and operators' perspective regarding sociocultural sustainability and the impacts of tourism. However, limited studies have addressed the intercultural competence of tourists interacting with different cultures. Second, a widely accepted domain is lacking, as is a complete measurement of tourists' intercultural competence. However, the specific intercultural competences demonstrated by tourists and its consequences remain underrepresented in the literature, creating difficulties in accessing and practicing appropriate tourist behavior in cultural tourism that may benefit guests and hosts. Third, the association between competence practices during cultural tourism and meaningful 
cultural experience is in urgent need. The manner in which tourists' intercultural competence can result in a memorable experience remains unclear. A well-developed instrument could indicate the influence of tourists' intercultural competence and active participation on the creation of a memorable experience. Accordingly, this research includes two studies, addressing two different research objectives. In Study 1, a scale for tourists' intercultural competence in the cultural tourism context was developed and validated. Study 2 examined the associations among tourists' intercultural competence, their active participation, and the memorable cultural experience. 


\section{Literature}

2.1 Role of tourists in cultural contact

Tourism essentially involves the voluntary movement of people (Mueller, Peters, and Weiermair 2009). Cultural tourism can be defined as "the movement of persons to cultural attractions away from their normal place of residence, with the intention to gather new information and experiences to satisfy their cultural needs" (Chen and Rahman 2018, p. 154). This definition implies that cultural tourism allows tourists to live, explore, and enjoy the difference of "the other" as well as to discover their own identity generated from home (Mueller, Peters, and Weiermair 2009; Urry 2002). Studies have investigated mobility with respect to time, space, and behavior in the tourism context (Hall 2005). However, relatively few studies have highlighted the role of the mental mobility of tourists and its influence on their behavior (Mueller, Peters, and Weiermair 2009).

Cultural contact, defined as "a predisposition for groups to interact with outsiders" (Cusick 1998), is an emerging concept in the tourism literature for understanding the purpose and depth of experience when tourists encounter different cultures (Gnoth and Zins 2013; McKercher 2002). Chen and Rahman (2018) defined cultural contact as "groups of tourists coming into or staying in contact for days in a particular cultural tourist destination." Contact between groups can boost mutual understanding, reduce prejudices, and improve intergroup relations (Allport 1954; Kirillova, Lehto, and Cai 2015). However, contact may not necessarily lead to positive results, and tension, hostility, and suspicion may be increased sometimes (Fan et al. 2017). Interaction between tourists and hosts could result in tourist role conflicts (Yu and Lee 2014). Consequently, role conflicts and role ambiguity put pressure on individuals (Thompson and Bunderson 2001). Accordingly, tourists' role in cultural contact deserves a systematic investigation. 
Generally, cultural tourists tend to encounter novel, authentic, and unique cultural products and are interested in gaining knowledge and diverse experiences (Reisinger 1994). On the other hand, cultural tourists not only involve in pursuing cultural experiences, but also undertaking the responsibility and obligation to preserve local culture and society (Featherstone 2002). They play the role of "tourist citizens" and improve relations between countries (Holmes 2001; Molz 2005). However, either cultural conflicts or mutual understanding can be stimulated through tourists' cross-cultural competence (Reisinger 2009; Tsaur, Yen, and Teng 2018; Ye, Zhang, Yuen 2013). Interactions between guests and hosts facilitate tourists having rewarding experiences and cultural understanding and influence the social and cultural life of the destination community (Su et al. 2016b). Thus, tourists' roles in cultural contact include enhancing cultural experience and facilitating positive cultural impacts. However, what specific competencies demonstrated by tourists in cultural contact and its consequence remain underrepresented in the literature.

\subsection{Assessing tourists' intercultural competence}

Intercultural competence, a general term used in intercultural communication, refers to "the ability to communicate effectively in cross-cultural situations and to relate appropriately in a variety of cultural contexts" (Bennett and Bennett 2004). It refers to "the skills and abilities that an individual needs in order to interact appropriately and efficiently with persons from a different culture" (Scherle and Nonnenmann 2008). With intercultural competence, individuals can distinguish between cultural differences and use their cultural knowledge to adjust their own behaviors to interact more effectively with people from different cultural backgrounds (Tsaur and Tu 2019).

Intercultural competence has received increasing attention in the tourism literature. However, the domain of this construct remains vague. As presented in Table 1, based on the definition of intercultural competence, this study reviewed the studies that have explored 
tourists' ability to interact with local people and cultural environment. Related concepts have been applied in the tourism literature, namely intercultural sensitivity (Donohoe 2011; Kirillova, Lehto, and Cai 2015), intercultural understanding (Kirillova, Lehto, and Cai 2015; Raymond and Hall 2008), tourists' appreciation (McIntosh 2004), cultural contact (Gnoth and Zins 2013), cultural mobility (Mueller, Peters, and Weiermair 2009), tourists' predisposition (Nowaczek and Smale 2010), and cosmopolitanism (Molz 2006; Swain 2009). In addition, those constructs have been respectively discussed in the cultural tourism, ecotourism, international tourism, and volunteer tourism contexts. The intercultural competence domain was used differently in different contexts. In this study, a multidimensional approach was adopted to holistically capture tourists' intercultural competence in the cultural tourism context. On the basis of the research context, concepts that targeted nature-based tourism, such as the tourists' predisposition, were excluded. The remaining concepts were deconstructed into different dimensions based on their definition and the items under the concept. For example, "cultural mobility" is defined as "travelers' interests and values towards cultural differences, and as real travel behavior in terms of traveling to culturally different regions and participating in local cultural events (Mueller, Peters, and Weiermair 2009)." Therefore, cultural mobility was deconstructed into intercultural appreciation and intercultural action. The items used by Ye, Zhang, and Yuen (2013) to measure "intercultural competence" include: understanding locals' world view, adopting the locals' perspective, adapting to local etiquette, and communicating with people. Therefore, intercultural competence (Ye, Zhang, and Yuen 2013) was deconstructed into intercultural understanding and intercultural action. Finally, four dimensions were considered as the essential components of tourists' intercultural competence: intercultural responsibility, understanding, appreciation, and action, and were subsequently evaluated through in-depth interviews and expert panel review. 
Intercultural responsibility represents the normative aspect of intercultural competence. From the perspective of cosmopolitanism, Molz (2006) argued that cosmopolitan tourists can be imagined as having "a sense of tolerance, flexibility, and openness toward otherness that characterizes an ethics of social relations in an interconnected world." In ecotourism research, Donohoe (2011) used the term "cultural sensitivity" to refer to ecotourists who implement, support, and participate in ecotourism. Ecotourists minimize impacts on natural and cultural environments, foster intercultural awareness and respect, protect built and living cultural heritage, foster the informed participation and empowerment of local and indigenous people, and respect the sociocultural value systems of the host community. Furthermore, Nowaczek and Smale (2010) developed the Ecotourist Predisposition Scale to explain and evaluate tourists' ecotourism predisposition. The results revealed that ecotourists' predisposition includes an ethical dimension concerning respect toward the natural environment and the local people as well as responsibility in travel choices, decisions, and consumptions. Therefore, intercultural responsibility refers to an ability to behave ethically, respect local cultures, maintain openness and tolerance toward others, and foster the informed participation of local people (Donohoe 2011; Molz 2006; Nowaczek and Smale 2010).

Intercultural understanding is "the basic ability of people to recognize, interpret and correctly react to people, incidences or situations that are open to misunderstanding due to cultural differences" (Kirillova, Lehto, and Cai 2015). Kirillova, Lehto, and Cai (2015) proposed "intercultural sensitivity" and described it as "an ability to discriminate and experience relevant culture difference" to investigate the relationship between interaction quality and intercultural sensitivity changes in volunteer tourism. The results revealed that the quality of interaction with the host community and volunteer tourism setting were linked to positive and negative changes in intercultural sensitivity, thereby has the potential to promote 
and inhibit intercultural understanding. The Developmental Model of Intercultural Sensitivity (DMIS) proposed by Bennett (1986) was utilized to measure intercultural sensitivity, including ethnocentric orientations (denial, defense, and minimization) and ethnorelative orientations (acceptance, adaptation, and integration).

Ye, Zhang, and Yuen (2013) modified a sociocultural adaptation scale to measure tourists' intercultural competence, such as understanding locals' world view, adopting the locals' perspective, adapting to local etiquette, and communicating with people. Their study revealed a negative correlation between perceived cultural distance and anticipated discrimination for tourists with relatively high intercultural competence. However, the measurement adopted in their study emphasizes understanding and adapting locals' world view, which represents the understanding aspect of tourists' intercultural competence. Moreover, from a cosmopolitanism perspective, Urry (1995) mentioned an increase in reflexivity in the physical and social world, and argued that aesthetic cosmopolitanism involving "an ability to locate one's own society and its culture in terms of a wide-ranging historical and geographical knowledge" enables one to "reflect upon and judge aesthetically between different natures, places, societies." Tourist and local gazes are adjusted according to the reflection on the other (Cave 2005). Thus, intercultural understanding refers to an ability to distinguish cultural differences, understand locals' world view, and reflect on cultural differences (Gnoth and Zins 2013; Kirillova, Lehto, and Cai 2015; Urry 1995; Ye, Zhang, and Yuen 2013).

Intercultural appreciation of a host culture can result from "exotic" cultural experiences and interaction with local people in a destination (McIntosh 2004). Gnoth and Zins (2013) conceptualized "interest in the other" as the focal issue of cultural tourism and developed a measurement to assess tourists' interest levels when exposed to a native culture. McIntosh (2004) gained an understanding of the appreciation for Maori culture through analyzing 
motivations, perceptions, and experiences. Motivation refers to the extent of tourists' motivation to understand Maori culture; perceptions refer to tourists' awareness, knowledge, and images or impressions held of that culture; and experiences refer to experiences of gazing, lifestyle, authenticity, personal interaction, and informal learning. In addition, curiosity toward different cultural, encounters with the "other," and aesthetic tastes as a global connoisseur are crucial elements of cosmopolitan tourists (Molz 2006; Swain 2009; Urry 1995). Therefore, intercultural appreciation refers to tourists' interest levels toward different cultures and ability to appreciate local cultures and lifestyles (Gnoth and Zins 2013; Molz 2006; Nowaczek and Smale 2010; Swain 2009; Urry 1995).

Finally, intercultural action represents specific actions undertaken by tourists to interact with locals. Tourists' understanding and appreciation of local culture can be facilitated by experiencing local culture and interacting with locals (McIntosh 2004). Nowaczek and Smale (2010) conceptualized authentic cultural encounters as a dimension of tourists' ecotourism predisposition. This includes learning about local customs and culture, participating in local customs and activities, becoming immersed in local culture, interacting with local people; and having new cultural experiences. McIntosh (2004) used experience as an aspect to understand tourists' appreciation, which includes experiences of gazing, lifestyle, authenticity, personal interaction, and informal learning. Gnoth and Zins (2013) also considered learning more about local cultures, interacting with locals, and becoming involved in local activities to assess tourists' interest in different cultures. Therefore, specific actions undertaken by tourists in intercultural interactions include learning information, participating in local activities; interacting with local people; and experiencing local authentic culture and lifestyle.

2.3 Relationships between intercultural competence, tourist active participation, and memorable cultural experience

A positive memorable tourism experience refers to "a tourism experience positively 
remembered and recalled after the event has occurred" (Kim, Ritchie, and McCormick 2012). Researchers and practitioners understand the importance of delivering memorable experiences. Tourism destinations should facilitate the destination environment to deliver memorable tourism experiences, thereby increasing their competitiveness (Kim 2014; Wei et al. 2019; Zhang, Wu, and Buhalis 2018). Kim, Ritchie, and McCormick (2012) developed a measurement specifically for memorable tourism experiences. This measurement included seven dimensions: hedonism, refreshment, local culture (refers to a good impression about local people and close experience with the local culture), meaningfulness, knowledge, involvement, and novelty. Furthermore, Kim and Ritchie (2014) conducted a cross-cultural comparison between American and Taiwanese university students and confirmed the validity of the memorable tourism experience scale. Studies have indicated that memorable tourism experience is a strong predictor of revisit intention, positive word of mouth, and future destination choices (Kim and Ritchie 2014; Kim, Ritchie, and Tung 2010; Zhang, Wu, and Buhalis 2018).

The antecedents of memorable tourism experience include perceived meaningfulness, opportunities to encounter local experiences, significance, novelty, opportunities for social interactions, local hospitality, serendipity and surprises, professionalism of local guides, and positive emotions (Chandralal and Valenzuela 2013). In general, external, social, and personal factors influence memorable tourism experience (Morgan and Xu 2009; Wei et al. 2019). Tourists' cultural experience depends on the cultural distance between hosts and guests as well as the way in which a tourist responds to cultural encounters; therefore, cultural interaction constructs memorable and meaningful experiences (Morgan and Xu 2009). Cultural contact represents tourist experience, and a higher level of cultural contact creates a more memorable tourism experience (Chandralal and Valenzuela 2013; Chen and Rahman 2018). 
Specifically, intercultural responsibility implies respecting local people and sociocultural value systems (Donohoe 2011) and maintaining openness toward others and cultural diversity (Molz 2006; Swain 2009). Therefore, tourists with intercultural responsibility should acknowledge the value of local cultures and demonstrate openness in pursuing cultural diversity, thus creating a memorable cultural experience. In addition, a memorable tourism experience reflects memorable cognitive and affective benefits received from tourism destinations, creating a bond between tourists and destinations (Zhang, $\mathrm{Wu}$, and Buhalis 2018). A deep understanding of local culture can create an authentic and memorable experience (Tung and Ritchie 2011) and bestow tourists with the ability to discriminate and understand authentic culture and comprehend locals' worldview (Kirillova, Lehto, and Cai 2015; Ye, Zhang, and Yuen 2013), thereby deepening tourists' comprehension of different cultures and enhancing their memories. Moreover, tourists' emotional and affective aspects are involved in the creation of a memorable tourism experience (Kim, Ritchie, and Mccormick 2012). Tourists's seek emotional responses to new experiences (Molz 2006). Appreciation of host culture results from tourists' emotional attachment to destinations (McIntosh 2004). The ability to appreciate different cultures generates emotional attachment for tourists, further creating a memorable cultural experience. Finally, experiencing local culture, interacting with local people, and learning about local culture and residents' way of life significantly enhances memorable cultural experiences (Chandralal and Valenzuela 2013; Morgan and Xu 2009; Kim and Ritchie 2014; Tung and Ritchie 2011). Accordingly, hypothesis 1 was developed. The relations between each dimension of intercultural competence and memorable cultural experience are further examined after the factor structure is identified through the development of an instrument.

H1: Tourists' intercultural competence is positively associated with a memorable cultural experience. 
Customer participation is defined as "the degree to which the customer is involved in producing and delivering the service" (Dabholkar 1990). Participative and interactive experiences have received increasing attention (Campos et al. 2018). Research has revealed that tourists' participation contributes to their satisfaction, loyalty, and experience co-creation (Mathis et al. 2016; Prebensen and Foss 2011; Prebensen and Xie 2017). In addition, active participation enhances tourists' long-lasting memories (Campos et al. 2018; Larsen 2007), allows tourists to immerse themselves in an experience through participation in activities physically or mentally, and enhances the memorability of experiences (Buonincontri et al. 2017; Campos et al. 2016; Tung and Ritchie 2011).

Tourists' active participation is described in terms of "the tourists' application of knowledge to improve skills," which requires tourists' personal and unique resources such as skills, competence, and knowledge (Aho 2001; Buonincontri et al. 2017; Campos et al. 2018). Active participation in tourist experience reflects the devotion of time and effort to producing the experience, which reveals the tourist's skills, knowledge, interests, and preferences (Prebensen, Vittersø, and Dahl 2013). As the level of tourists' participation increases, they become more likely to manage their personal skills and resources to address problems during participation, eventually leading to rewarding experiences ( $\mathrm{Su}$ et al. 2016a). Therefore, tourists can participate in cultural experience by demonstrating their intercultural competences and creating memorable cultural experiences. Thus, hypotheses 2 and 3 were proposed. The mediating effects of tourists' active participation on the relations between each dimension of intercultural competence and memorable cultural experience were further examined after the factor structure was identified through the development of an instrument (H4). The research model is shown in figure 1.

H2: Tourists' intercultural competence is positively associated with tourists' active participation. 
H3: Tourists' active participation is positively associated with a memorable cultural experience.

H4: Tourists' active participation plays a mediating role between tourists' intercultural competence and memorable cultural experience.

Insert Figure 1 Here 


\section{Research Design}

The research was divided into two stages according to the research questions and objectives. In Study 1, qualitative and quantitative research methods were adopted to construct a measurement for tourists' intercultural competence. The measurement developed in Study 1 was used in Study 2 to examine the relation among tourists' intercultural competence, active participation, and memorable cultural experience. The following sections detail the methods and results of both studies. 
This study followed the scale development procedure adopted by Churchill (1979). The following three steps were taken: (1) item generation, (2) initial data collection and measurement purification, (3) second data collection and measurement verification (Figure 2).

Insert Figure 2 Here

\subsection{Item generation}

The scope of the construct being developed must be precisely described in the first stage of scale development to delineate items that are included and excluded (Churchill 1979). In this study, a multidimensional approach was adopted to develop a scale for tourists' intercultural competence. Scherle and Nonnenmann (2008) defined tourists' intercultural competence as "the abilities that a tourist needs to interact appropriately and efficiently with a different culture.” Four previously described dimensions were included as the essential components of tourists' intercultural competence: intercultural responsibility, intercultural understanding, intercultural appreciation, and intercultural action.

Items were generated from both literature and interviews. First, literature related to tourist intercultural competence was scanned (Table 1) and applicable measurement items were retained to form the item pool for further review. Second, semi-structured in-depth interviews were adopted to generate rich information of the measurement scale. Purposive sampling was firstly used to determine eligible respondents. Taiwanese tourists with rich experiences in cultural tourism were targeted. Respondents were recruited through social media (such as BBS and Facebook) and were selected based on the professional judgement of the researchers according to their travel destinations, frequency, experience, purposes and other relevant travel information. Secondly, by following snowball sampling, respondents 
were asked to invite people in their social network to recruit qualified respondents. Two sections were included in the interviews. First, interviewees were asked to describe their experiences in travel, and to share their experience regarding their encounters with different cultures. Thereafter, interviewees were requested to talk about their understanding of intercultural competence with reference to their own travel experience. They were further asked to give examples of intercultural competence practices from themselves or from others they observed. Specific interview questions included: How did you gather information and understand the knowledge of different cultures in travel? How do you understand intercultural competence? Please elaborate. In your trip, did you demonstrate any aspect of intercultural competence? If yes, could you please give some examples? If not, have you observed others to demonstrate intercultural competence in travel? If yes, please give examples. Data collection was stopped after information saturation was reached. For this purpose, 27 qualified informants were interviewed. The information derived from transcripts could be classified into the four categories based on the literature review and transferred into the measurement items.

As a result, 14 items were generated from literature and 12 items were newly developed from interviews (Table 2). An initial list of items was compiled that potentially related to tourists' intercultural competence. Twenty-six items had been generated at this step. An expert panel review was conducted to further evaluate content validity. A six-person panel comprising scholars of tourism research and tourism industry personnel with expertise in intercultural studies, cultural tourism, and related research methods was invited to evaluate the existing items. Scores were provided for each item using a 3-point Likert-type scale ranging from "inappropriate" to "appropriate." In this step, 13 of 26 items were modified to improve the understandability and appropriateness of the instrument; and one of them were deleted, and no new items emerged. 
Insert Table 2 Here

Furthermore, to avoid potential problems about content, wording and design of the questionnaire, 12 graduate students ( 5 male and 7 female) were requested to check all the items. None of them were authors of this paper, and none were involved in the initial item generation. On the basis of participants' feedback, three items were modified; no new items emerged. Therefore, 25 measurement items generated in this step were adopted as the research instrument for part two.

4.2 Data collection (phase one) and measurement purification

According to Churchill (1979), an iterative scale purification procedure was used to develop a reduced, more parsimonious scale. Items were scored on a 5-point Likert scale ranging from 1 (extremely disagree) to 5 (extremely agree). A convenience sample of five university students who have traveled to Taiwan-based cultural tourism destinations within one year was chosen as the phase one sample for the item purification. Exploratory factor analysis (EFA) aims to reduce the number and to explore the dimensionality of items (Costello and Osborne 2005). Homogeneous groups such as student samples allow researchers to reduce the possibilities of introducing variance unrelated to the scale items that may be inflated by confounding factors (Mills, Kook Lee, and Douglas 2007; Nowaczek and Smale 2010). Thus, student samples are useful for concept identification and primary construct analysis (Emory 1980). University student samples have been used on the studies of personal values, attitudes, and experiences, especially in the fields of consumer behavior and marketing (Kim, Ritchie, and Tung 2010; Mills, Kook Lee, and Douglas 2007). For example, Kim, Ritchie, and Tung (2010) used student sample to conduct EFA and confirmatory factor analysis (CFA) to develop a memorable experience scale. In addition, Wang, Cole, and Chen (2018) accessed tourists' innovation in air travel with student sample for the EFA and tourist sample for the CFA. As a result, 341 valid responses were collected. 
An exploratory factor analysis was applied to the collected data to reduce the number of items. The Kaiser-Meyer-Olkin (KMO) test and the Bartlett sphericity test were performed to verify that the data were amenable to factor analysis. The KMO index was 0.906 , and the Bartlett's test of sphericity was significant at the level of 0.000 , justifying the use of EFA (Hair et al. 2010). As presented in Table 3, the following four factors with eigenvalues greater than 1 were extracted: intercultural responsibility (six items), intercultural understanding (five items), intercultural appreciation (five items), and intercultural action (five items). The cumulative percentage of the explained variance was $56.8 \%$. Four items with a factor loading lower than 0.45 (Hair et al. 2010) or loading on two factors (Lewis, Templeton, and Byrd 2005) were excluded. The EFA process produced a four-factor and 21-item scale. The coefficient $\alpha$ value for each factor ranged from 0.774 to 0.849 , indicating reasonable reliability (Bagozzi and Yi 1988). The value indicated acceptable internal consistency (Nunnally and Bernstein 1994).

\section{Insert Table 3 Here}

4.3 Data collection (phase two) and measurement verification

Churchill (1979) suggested that after scale items have been refined, the items should be re-examined using different samples to verify the reliability and validity. Accordingly, a phase two survey was conducted with onsite tourists to confirm the factor structure of tourists' intercultural competence scale.

To control the potential impact from respondents' nationality/cultural background, Taiwanese tourists who traveled to three famous cultural destinations in Taiwan were chosen to participate in the survey. Mei-Nong (Kaohsiung), Sanyi (Miaoli), and Alishan (Chiayi) are respectively famous cultural destinations because of its aborigines and Hakka culture. Aborigine and Hakka culture destinations have received increasing popularity because these 
ethnic groups are seen as unique to the mainstream heluo culture in Taiwan (Hou, Lin, and Morais 2005). Taiwan has a rich and complex indigenous culture (Xie, $\mathrm{Wu}$, and Hsieh 2012). Hakka culture has distinctive language, music, dance, crafts, and architecture, showing that Hakka culture are distinct and representative (Liau 2014).

Tourists are attracted to Mei-Nong and Sanyi because of its Hakka culture. $80 \%$ of tourists expressed the attractiveness of Hakka culture in Mei-Nong, and the main draws for tourists to Sanyi also include Hakka customs (Hsiao and Chuang 2016; Liau 2014). Alishan is an important tourist and recreational area in Taiwan, and possesses a rich Tsou indigenous culture (Chang, Hung and Chou 2018). Tsou indigenous culture has become the highlight of Alishan to attract tourists (The Central News Agency 2020). Therefore, this study took the three cultural destinations in Taiwan for the data collection.

Data were collected on-site at the reception of hotels at the three selected destinations from January to May 2019. Tourists were asked to answer the questionnaire anonymously and individually when they checked out. The period included both weekdays and weekend to ensure the reasonable combination of individual travelers, package tourists and family tourists. Accordingly, 367 valid questionnaires were gathered and analyzed. All of them were Taiwanese. Women and men constituted $57.5 \%$ and $42.5 \%$ of the respondents, respectively. Furthermore, $41 \%$ of the respondents were aged below 30 years; $25 \%$ were aged between 31 and 40 years; $18 \%$ were aged between 41 and 50 years; and 11\% were aged between 51 and 60 years. Of the respondents, $61 \%$ had acquired college or university education, followed by $22 \%$ with high school education.

A confirmatory factor analysis (CFA) with maximum likelihood estimation was conducted for estimating the parameters of the measurement model (Jöreskog and Sörbom 1993). Additionally, the convergent and discriminant validity of the scale were further examined. The CFA results indicated that the tourists' intercultural competence scale 
demonstrated favorable goodness of fit $\left(\chi^{2}=467.22, \mathrm{df}=183, \chi^{2} / \mathrm{df}=2.55, \mathrm{GFI}=0.89, \mathrm{AGFI}\right.$ $=0.86, \mathrm{PGFI}=0.71, \mathrm{SRMR}=0.047, \mathrm{RMSEA}=0.065, \mathrm{NFI}=0.97, \mathrm{NNFI}=0.98, \mathrm{RFI}=0.96$, $\mathrm{CFI}=0.98, \mathrm{IFI}=0.98$, and $\mathrm{CN}=188.55)$.

As indicated in Table 3, the composite reliability of each construct ranged from 0.827 to 0.888, which was higher than 0.7 , indicating acceptable internal consistency (Fornell and Larcker 1981). The factor loading of each item was higher than 0.5 (ranged from 0.61 to 0.83). All factor loadings significantly differed from zero $(\mathrm{p}<.05)$, as evidenced by consistently large t values (range: 11.48 to 18.78 ). Alhough the ideal average variance extracted (AVE) for a well-developed construct should be above 0.5, it is suggested that AVE value of a newly developed scale should be higher than 0.45 (Netemeyer, Bearden, and Sharma 2003), The AVE for each construct ranged from 0.490 to 0.616 ; therefore, convergent validity was established (Bagozzi and Yi 1988). The square root of the AVE for each construct was higher than the correlation coefficient between any two constructs (Table 4), thereby confirming the discriminant validity of the measurement scale (Hair et al. 2010). Therefore, the measurement model in this study had acceptable reliability and validity.

Insert Table 4 Here 


\section{Study Two: Structural Model Examination}

Study 2 further examined the relationship among tourists' intercultural competence, active participation, and memorable cultural experience. For all measures, a 5-point Likert scale was used ranging from 1 (strongly disagree) to 5 (strongly agree). Tourists' intercultural competence was measured using the scale constructed in Study 1. Preexisting scales were used to measure tourists' active participation and memorable cultural experience. Specifically, three items developed by Buonincontri et al. (2017) were adapted to measure active participation of tourists during their experiences. These included "My tourism experience was enhanced because of my participation in cultural and tourist activities," "I enjoy taking a hands-on approach during my tourism experience," and "I have sought out situations that challenge my skills and abilities during this trip." In addition, three items from the scale of memorable tourism experiences developed by Kim, Ritchie, and Mccormick (2012) were adapted. Items included "Good impressions about the local people," "Closely experienced the local culture," and "Local people in a destination were friendly."

The proposed structural model based on the hypotheses was assessed using path analysis, and the indices obtained suggested a well-fitted model $\left(\chi^{2}=597.26, \mathrm{df}=242, \chi^{2} / \mathrm{df}\right.$ $=2.47, \mathrm{GFI}=0.88, \mathrm{AGFI}=0.85, \mathrm{PGFI}=0.71, \mathrm{SRMR}=0.048, \mathrm{RMSEA}=0.063, \mathrm{NFI}=0.97$, $\mathrm{NNFI}=0.98, \mathrm{RFI}=0.96, \mathrm{CFI}=0.98, \mathrm{IFI}=0.98$, and $\mathrm{CN}=188.31)$. Figure 3 depicts the estimated path coefficients from structural equation modeling (SEM). The results indicated that tourists' intercultural competence significantly and positively influenced memorable cultural experience $(\beta=0.20, \mathrm{t}=2.21, \mathrm{p}<0.05$ for intercultural responsibility; $\beta=0.27, \mathrm{t}=$ 2.71, $\mathrm{p}<0.01$ for intercultural understanding; $\beta=0.18, \mathrm{t}=2.09, \mathrm{p}<0.05$ for intercultural appreciation; $\beta=0.26, \mathrm{t}=2.47, \mathrm{p}<0.05$ for intercultural action; $\left.\mathrm{R}^{2}=0.65\right)$. Therefore, the results supported Hypothesis 1 . Tourists with a higher level of intercultural competence have a more memorable cultural experience. 
Insert Figure 3 Here

From an investigation of the mediating effect of tourists' active participation on the relation between intercultural competence and memorable cultural experience, Hypothesis 1 was supported. The proposed structural model based on the hypotheses was assessed using path analysis, and the indices obtained suggested a well-fitted model $\left(\chi^{2}=706.65\right.$, df $=309$, $\chi^{2} / \mathrm{df}=2.29, \mathrm{GFI}=0.87, \mathrm{AGFI}=0.85, \mathrm{PGFI}=0.72, \mathrm{SRMR}=0.046, \mathrm{RMSEA}=0.059, \mathrm{NFI}=$ $0.97, \mathrm{NNFI}=0.98, \mathrm{RFI}=0.97, \mathrm{CFI}=0.98, \mathrm{IFI}=0.98$ and $\mathrm{CN}=200.21)$. Figure 3 illustrates the estimated path coefficients form SEM. The results indicated that tourists' intercultural competence significantly and positively influences tourists' active participation $\left(\beta=0.17^{*}, \mathrm{t}\right.$ $=2.00, \mathrm{p}<0.05$ for intercultural responsibility; $\beta=0.32^{* *}, \mathrm{t}=3.25, \mathrm{p}<0.01$ for intercultural understanding; $\beta=0.22 * *, t=2.67, \mathrm{p}<0.01$ for intercultural appreciation; $\beta=0.20 *, \mathrm{t}=$ $2.00, \mathrm{p}<0.05$ for intercultural action; $\left.\mathrm{R}^{2}=0.67\right)$. Furthermore, tourists' active participation significantly and positively influenced the memorability of cultural experiences $(\beta=0.50, t=$ $\left.5.54^{* *}, \mathrm{p}<0.01 ; \mathrm{R}^{2}=0.74\right)$ (Figure 4).

\section{Insert Figure 4 Here}

The statistical methods used to assess mediation effects include hierarchical regression (Baron and Kenny 1986) and SEM (Hair et al. 2010). The Sobel test (Sobel 1982) is one of the best for assessing mediation effects, especially with regard to structural equation models (Veasna, Wu, and Huang 2013); thus, the Sobel test was employed in this study. The z-test results for the mediating effect of tourists' active participation on the relation between intercultural competence and memorable cultural experience are detailed in Table 5 ( $\beta=$ $0.09^{*}$, z-test $=1.99, \mathrm{p}<0.05$ for intercultural responsibility; $\beta=0.16^{* *}, \mathrm{z}$-test $=2.77, \mathrm{p}<$ 0.01 for intercultural understanding; $\beta=0.11^{*}$, z-test $=2.47, p<0.05$ for intercultural appreciation; $\beta=0.10, z$-test $=1.88$ for intercultural action). The Sobel test results indicated that tourists' active participation plays a mediating role in the relationships between 
intercultural responsibility, understanding, and appreciation and having a memorable cultural experience.

\section{Insert Table 5 Here}

A competing model was adopted to compare the partial mediation model and full mediation model to further confirm the results of the Sobel test (Veasna, Wu, and Huang 2013). The $\Delta \chi^{2}$ difference between the partial mediation model and full mediation model $\left(\Delta \chi^{2}\right.$ $=723.79-706.65=17.14, \Delta \mathrm{df}=4 ; \mathrm{p}<0.01)$ suggested that the partial mediation model performed significantly better than the full mediation model. In addition, compared with the direct effects between intercultural competence and memorable cultural experience, the regression coefficient was lower and nonsignificant in the mediation model $(\beta=0.20 *$ to 0.12 for intercultural responsibility; $\beta=0.27^{* *}$ to 0.12 for intercultural understanding; $\beta=0.18^{*}$ to 0.07 for intercultural appreciation). Therefore, the results supported hypotheses $2 \mathrm{a}, 2 \mathrm{~b}$, and 2c: the mediating effects of tourists' active participation on the relationships between intercultural responsibility, appreciation, understanding and memorable cultural experience were supported. Regarding intercultural action, the Sobel test indicated a nonsignificant effect, implying that active participation did not act as a mediator between intercultural action and memorable cultural experience. Hypothesis $2 \mathrm{~d}$ was not supported. 


\section{Discussion}

In this study, a multidimensional measurement was developed for measuring tourists' intercultural competence. Four factors of intercultural competence were identified: intercultural responsibility, intercultural understanding, intercultural appreciation, and intercultural action. Furthermore, the relationships between among tourists' intercultural competence, tourists' active participation, and memorable cultural experience were investigated.

The significance of responsibility and ethical behaviors during tours has been valued in the literature. This study is one of the first attempts to capture and measure tourists' responsibility as a competence toward cultural environments. Tourists' intercultural responsibility represents the normative aspect of intercultural competence. Tourists with intercultural responsibility are expected to acknowledge the value of local cultures, demonstrate openness in pursuing cultural diversity, and minimize negative impacts on local cultural environments. Regarding the ecotourism context, Nowaczek and Smale (2010) developed a scale for ecotourists" predisposition. They used "ethics" as a dimension and indicated that ecotourists must "behave ethically" and "show much respect" toward natural areas and local people. However, to our knowledge, limited studies have identified the domain and offered a specialized measurement for tourists' intercultural responsibility. The findings showed consistency with previous literature, which argued that cultural tourists must behave ethically, respect local cultures, maintain openness and tolerance toward others, and foster the informed participation of local people (Donohoe 2011; Molz 2006; Nowaczek and Smale 2010).

The concepts of intercultural understanding, intercultural appreciation, and intercultural action have been respectively applied with different terms and in different contexts. Such as intercultural competence (Ye, Zhang, and Yuen 2013), intercultural sensitivity (Donohoe 
2011; Kirillova, Lehto, and Cai 2015), intercultural understanding (Kirillova, Lehto, and Cai 2015; Raymond and Hall 2008), tourists' appreciation (McIntosh 2004), cultural contact (Gnoth and Zins 2013), and cultural mobility (Mueller, Peters, and Weiermair 2009). Consequently, the domain of these concepts has vague, overlapping, and inconsistent domain settings. Therefore, a multidimensional approach was adopted in this study, and the domain of tourists' intercultural competence was captured and conceptualized into different factors.

The results of the measurement development correspond to past scales related to intercultural competence. Ye, Zhang, and Yuen (2013) utilized a single dimension to measure intercultural competence. Items included understanding locals' world view, viewing things from the locals' perspective, adapting to local etiquette, and communicating with people; these can be achieved through intercultural understanding and action factors. Kirillova, Lehto, and Cai (2015) utilized the DMIS to measure the intercultural sensitivity of volunteer tourists. This included ethnocentric orientations (denial, defense, and minimization) and ethnorelative orientations (acceptance, adaptation, and integration), which can be represented through intercultural responsibility and understanding factors presented in this study. Specifically, being open-minded and tolerant means not to deny the value of exotic culture and not to be defensive about different cultures. Being aware of and comparing differences between hosts and guest cultures means not minimizing cultural differences. Moreover, accepting and reflecting cultural differences, viewing things from local people's perspectives, and learning about cultural advantages represent acceptance, adaptation, and integration dimensions, respectively. In addition, Gnoth and Zins (2013) developed a cultural contact scale to conceptualize and measure cultural tourists' interest levels when exposed to a different culture. The items reflected tourists' interest toward different cultures and willingness to interact, which can be represented by intercultural appreciation and action factors presented in this study. 
Past studies often considered tourists' intercultural understanding and appreciation as the consequences of tourism experience. For example, Kirillova, Lehto, and Cai (2015) argued that host community and volunteer tourism setting have the potential to facilitate intercultural sensitivity and intercultural understanding of volunteer tourists. Raymond and Hall (2008) argued that volunteer tourism sending organizations could play an important role in facilitating the cross-cultural understanding of tourists through volunteer tourism. Moreover, McIntosh (2004) investigated tourists' appreciation for Maori culture after indigenous tourism through analyzing motivations, perceptions, and experiences. Different from previous studies, this study conceptualized tourists' intercultural understanding and appreciation as their competences, which represent the abilities to interact with different cultures, and enable them to create better tourism experience. The findings from this research suggest that developments of intercultural understanding and appreciation should not be perceived as natural results of cultural tourism, the efforts from tourists through demonstrating their competences are needed.

The Study 2 results revealed that tourists' intercultural competence was positively associated with memorable cultural experience. This implies that tourists play a key role in developing a rewarding cultural experience (Su et al. 2016b) and in cultural exchange. Past study has indicated that mutual understanding can be stimulated and negative experience can be avoided depending on certain intercultural competences (Tsaur, Yen, and Teng 2018; Ye, Zhang, and Yuen 2013). Furthermore, Morgan and Xu (2009) argued that social interaction is a component of memorable experience and stated that tourists' memorable and meaningful cultural experience depends on the cultural distance between hosts and guests as well as on a tourist's response to cultural encounter (Morgan and Xu 2009). This study provides empirical evidence that tourists' intercultural competence enables them to create positive and memorable tourism experiences. Moreover, in the cultural tourism context, normative 
intercultural responsibility becomes an important aspect of tourists' competence. Tourists have an obligation to respect and preserve local culture and society (Featherstone 2002). This involves regulating tourists' behavior and facilitating tourist activities to maintain openness and tolerance toward different cultures, leading to positive cultural experiences.

Furthermore, tourists' active participation plays a mediating role between tourists' intercultural competence and memorable cultural experience. Corresponding to previous studies, tourists can manage their personal skills, knowledge, interest, and preferences, spending time and effort in actively participating in rewarding tourism experiences (Prebensen, Vittersø, and Dahl 2013; Su et al. 2016a). Thus, this study illustrates the manner in which tourists produce memorable experiences through using intercultural competences. Specifically, the results revealed that the mediating effects of tourists' active participation affect the relationships between intercultural responsibility, intercultural understanding, intercultural appreciation, and memorable cultural experiences. However, no significant mediation effect was noted in the relationship between intercultural action and memorable cultural experiences. The results are understandable because intercultural responsibility, intercultural understanding, and intercultural appreciation represent the implicit abilities of tourists, whereas intercultural action represents outer behavioral predisposition. The demonstration of inner competences (namely intercultural responsibility, intercultural understanding, and intercultural appreciation) leads to intellectual and emotional involvement within tourists, thereby enhancing their perception of active participation and creating a memorable experience. However, intercultural action can directly lead to a memorable cultural experience without the involvement of other activities as mediators, such as active participation. Therefore, the effect of intercultural action on memorable experience is not necessarily evoked through tourists' active participation. 


\section{Conclusion}

Through adopting qualitative and quantitative approaches, a multidimensional measurement of tourists' intercultural competences was developed and validated. Four factors of tourists' intercultural competence were identified: intercultural responsibility, understanding, appreciation, and action. Two samples were tested to determine the goodness of fit, reliability, and validity of the scale. Study 2 validated the applicability of the scale for assessing tourists' intercultural competence developed in Study 1. Further, a theoretical framework was constructed for tourists' intercultural competence. The relationships between tourists' intercultural competence and memorable cultural experience were examined as were the mediating effects of tourists' active participation. Thus, the results of this study provide rich implications for academics and practitioners.

Academically, this study contributes to the cultural tourism literature by highlighting that cultural tourists require a certain level of cultural competence while consuming cultural materials (Richards 2018). A multidimensional measurement of tourists' intercultural competence was developed in this study. The holistic multidimensional measurement with convergence and discriminant validity presented in this study is expected to fully capture the structure of tourists' intercultural competence and enable scholars and practitioners to efficiently assess cultural tourists. In addition, the study conceptualized tourists' intercultural responsibility as a dimension of intercultural competence and revealed that responsibility toward different cultures regulates tourist behavior and enhances tourists' cultural experience by them showing respect, openness, and tolerance. Furthermore, empirical evidence of the relationships between tourists' intercultural competence, active participation, and memorable cultural experiences was provided. Past studies mentioned that intercultural competence decreases cultural distance, conflict, and discrimination (Tsaur, Yen, and Teng 2018; Ye, Zhang, and Yuen 2013). The results of this study revealed that intercultural competence also 
creates memorable cultural experiences. Finally, this study illustrates that tourists' active participation plays a mediating role in the relationship between intercultural competence and memorable cultural experiences. Specifically, mediating effects were observed between implicit intercultural competence (i.e., intercultural responsibility, understanding, and appreciation) and memorable cultural experiences. This psychological mechanism leads to the active participation of cultural tourists and further produces memorable cultural experiences. Thus, the manner in which cultural tourists interact with different cultures and create memorable cultural experiences was established.

From a practical perspective, this study provides implications for destination management. First, the study results help tourism operators to assess different aspects and degrees of intercultural competence that tourists demonstrate during the tour. This enables tourism operators to understand the characters of their tourism resources and products as well as frame marketing strategies and design travel activities (or products) according to the competence requirements of local tourism resources and individual needs. For example, Finland has launched a tourist pledge, asking tourists to promise that they will respect and treasure the Finnish nature, inhabitants, and culture. Statements such as "On my journey I pledge to be like a Finn, and by this, I mean slowing down from within," and "I shall also respect the lives of locals, and will be considerate with cameras or loud vocals" were drafted according to Finland's circumstances. The measurement proposed in this study can be used as a guideline to develop a cultural destination's rules or a pledge for tourists. In addition, efforts on the part of organizations must be devoted to creating memorable experiences for tourists (Buonincontri et al. 2017). The results revealed that intercultural responsibility, intercultural understanding, and intercultural appreciation could help create memorable cultural experiences through active participation. Destinations can employ guiding or educational programs (such as exhibits in visitor centers, brochures, onsite activities, and 
guiding services) to motivate tourists to demonstrate corresponding intercultural competences according to the local scenario and tourism resources. Designing more culturally attractive activities, such as creative cultural performances in China, gastronomy classes and rice farming in Thailand, and wine tasting and making seminars in Spain, can also help enhance the positive memorable experience for the tourists. Moreover, the results can help employees evaluate their customers' behavior and appropriately respond to induce tourists' intercultural competence. Finally, the results can be used to assist tourists in self-evaluating their characteristics of intercultural competence and improving their weak aspects to ensure tourists have a smooth trip and acquire a memorable experience.

Some limitations should be noted. First, this study is framed in the specific cultural context, which is Taiwanese visiting cultural destinations in Taiwan. As intercultural competence could be potentially influenced by tourist-host cultural distance, the instrument proposed in this study may require further examination in other nationalities, destinations, or cultural contexts to generalize the findings. The potential moderating effect of cultural distance on the relationship between intercultural competence and memorable cultural experiences also deserves further exploration. Second, this study analyzes tourists' perspectives, which might not reflect the competence that hosts and destinations preferred. Future research is encouraged to incorporate the perspectives of residents, destination managers, or staff to further confirm the results. Moreover, this study adopted the cultural dimension of Kim, Ritchie, and Mccormick's (2012) MTES. Future studies are encouraged to refine the measurement of memorable cultural experiences within the context of cultural tourism. Finally, although the psychological mechanism of intercultural competence within tourists has been tested, intercultural competence can be stimulated by managerial factors, such as tour guides or travel information. Cultivating intercultural competence as a part of destination management also warrants future investigation. In response to the rapid development of COVID-19, tourist behavior may have temporarily 
altered due to the restricted travel conditions and limited contact opportunities. However, as tourists' intercultural competence is an accumulated ability and a long lasting concept, the interruption of COVID-19 is very unlikely to change the competence-behavior-experience mechanism developed in this study. 
Reference

Aho, S. K. 2001. "Towards a General Theory of Touristic Experiences: Modelling Experience Process in Tourism." Tourism Review 56 (3/4): 33-37.

Allport, G. 1954. The Nature of Prejudice. Cambridge, MA: Addison-Wesley Publishing.

Bagozzi, R. P., and Y. Yi. 1988. “On the Evaluation of Structural Equation Models.” Journal of the Academy of Marketing Science 16 (1): 74-94.

Baron, R. M., and D. A. Kenny. 1986. "The Moderator-Mediator Variable Distinction in Social Psychological Research: Conceptual, Strategic, and Statistical Considerations." Journal of Personality and Social Psychology 51 (6): 1173.

Bennett, J. M., and M. J. Bennett. 2004. “Developing Intercultural Sensitivity.” In Handbook of Intercultural Training, edited by J. M. Bennett, M. J. Bennett, and D. Landis, 147165. Thousand Oaks, CA: Sage.

Boyd, S. 2002. "Cultural and Heritage Tourism in Canada: Opportunities, Principles and Challenges." Tourism and Hospitality Research 3 (3): 211-233.

Buonincontri, P., A. Morvillo, F. Okumus, and M. Van Niekerk. 2017. "Managing the Experience Co-Creation Process in Tourism Destinations: Empirical Findings from Naples.” Tourism Management 62:264-277.

Campos, A. C., J. Mendes, P. O. D. Valle, \& N. Scott. 2018. “Co-Creation of Tourist Experiences: A Literature Review.” Current Issues in Tourism 21 (4): 369-400.

Campos, A. C., J. Mendes, P. O. Do Valle, and N. Scott. 2016. "Co-Creation Experiences: Attention and Memorability." Journal of Travel and Tourism Marketing 33 (9): 13091336.

Cave, J. 2005. “Conseptualising Otherness as a Management Framework for Tourism enterprise." In Indigenous Tourism: The Commodification and Management of Culture, edited by C. Ryan and M. Aicken, 261-280. Oxford: Elsevier. 
Chandralal, L., and F. R. Valenzuela. 2013. "Exploring Memorable Tourism Experiences: Antecedents and Behavioural Outcomes." Journal of Economics, Business and Management 1 (2): 177-181.

Chang, H. M., C. H. Hung, and C. L. Chou. 2018. "A Study of Alishan Indigenous Tribal Tourism Development in Taiwan." Asian Journal of Environment \& Ecology 8 (1): 112.

Chen, H., and I. Rahman. 2018. "Cultural Tourism: An Analysis of Engagement, Cultural Contact, Memorable Tourism Experience and Destination Loyalty.” Tourism Management Perspectives 26:153-163.

Churchill Jr, G. A. 1979. “A Paradigm for Developing Better Measures of Marketing Constructs." Journal of Marketing Research 16 (1): 64-73.

Costello, A. B., and J. Osborne. 2005. "Best Practices in Exploratory Factor Analysis: Four Recommendations for Getting the Most from Your Analysis." Practical Assessment, Research, and Evaluation 10 (1): 7.

Cusick, J. G. 1998. “Introduction.” In Culture Contact: Interaction, Culture Change, and Archaeology, edited by J. G. Cusick, 1-20. Carbondale: Southern Illinois University. Dabholkar, P. 1990. “How to Improve Perceived Quality by Improving Customer Participation.” In Developments in Marketing Science, edited by B. J. Dunlap, 483487. NC: Cullowhee.

Donohoe, H. M. (2011). “Defining Culturally Sensitive Ecotourism: A Delphi Consensus.” Current Issues in Tourism, 14 (1): 27-45.

Emory, W. C. 1980. Business Research Methods. Burr Ridge, IL: Richard D. Irwin.

Fan, D. X., H. Q. Zhang, C. L. Jenkins, and P. M. Lin. 2017. "Does Tourist-Host Social Contact Reduce Perceived Cultural Distance?” Journal of Travel Research 56 (8): 998-1010. 
Featherstone, M. 2002. "Cosmopolis: An Introduction.” Theory, Culture and Society 19:1-16. Fornell, C., and D. F. Larcker. 1981. "Evaluating Structural Equation Models with Unobservable Variables and Measurement Error. Journal of Marketing Research, 18 (1): $39-50$.

Gnoth, J., and A. H. Zins. 2013. “Developing a Tourism Cultural Contact Scale.” Journal of Business Research 66 (6): 738-744.

Hair, J. F., W. C. Black, B. J. Balin, and R. E. Anderson. 2010. Multivariate Data Analysis. NY: Maxwell Macmillan International Editions.

Hall, C. M. 2005. Tourism: Rethinking the Social Science of Mobility. Harlow: Pearson Education.

Holmes, D. 2001. "Virtual Globalization: An Introduction.” In Virtual Globalization: Virtual Spaces/Tourist Spaces, edited by D. Holmes, 1-54. London: Routledge.

Hou, J. S., C. H. Lin, and D. B. Morais. 2005. “Antecedents of Attachment to a Cultural Tourism Destination: The Case of Hakka and Non-Hakka Taiwanese visitors to PeiPu, Taiwan.” Journal of Travel Research 44 (2): 221-233.

Hsiao, T. Y., and C. M. Chuang. 2016. "The Cooperation Model between Tourism Development and Traditional Culture: New Perspectives on Regional Context." Journal of Tourism and Cultural Change 14 (2): 91-106.

Jöreskog, K. G., and D. Sörbom. 1993. LISREL 8: Structural Equation Modeling with the SIMPLIS Command Language. Hillsdale: Scientific Software International.

Kim, J. H. (2014). “The Antecedents of Memorable Tourism Experiences: The Development of a Scale to Measure the Destination Attributes Associated with Memorable Experiences." Tourism Management 44:34-45.

Kim, J. H., and J. B. Ritchie. 2014. "Cross-Cultural Validation of a Memorable Tourism Experience Scale (MTES).” Journal of Travel Research 53 (3): 323-335. 
Kim, J. H., J. B. Ritchie, and B. Mccormick. 2012. "Development of a Scale to Measure Memorable Tourism Experiences." Journal of Travel Research 51 (1): 12-25.

Kim, J. H., J. R. Ritchie, and V. W. S. Tung. 2010. "The Effect of Memorable Experience on Behavioral Intentions in Tourism: A Structural Equation Modeling Approach.” Tourism Analysis 15 (6): 637-648.

Kirillova, K., X. Lehto, and L. Cai. 2015. "Volunteer Tourism and Intercultural Sensitivity: The Role of Interaction with Host Communities." Journal of Travel and Tourism Marketing 32 (4): 382-400.

Larsen, S. 2007. “Aspects of a Psychology of the Tourist Experience.” Scandinavian Journal of Hospitality and Tourism 7 (1): 7-18.

Lewis, B. R., G. F. Templeton, and T. A. Byrd. 2005. “A Methodology for Construct Development in MIS Research.” European Journal of Information Systems 14 (4): $388-400$.

Liau, S. J. 2014. "The Planning of Cultural Resources and Issues of Cultural Tourism in Meinong." Annals of Leisure and Recreation Research 6 (1): 41-74.

Mathis, E. F., H. L. Kim, M. Uysal, J. M. Sirgy, and N. K. Prebensen. 2016. "The Effect of Co-Creation Experience on Outcome Variable.” Annals of Tourism Research 57:6275.

Mcintosh, A. J. 2004. “Tourists' Appreciation of Maori Culture in New Zealand.” Tourism Management 25 (1): 1-15.

Mckercher, B. 2002. “Towards a Classification of Cultural Tourists.” International Journal of Tourism Research 4 (1): 29-38.

Mills, J. E., J. Kook Lee, and A. C. Douglas. 2007. "Exploring Perceptions of US State Tourism Organizations' Web Advertising Effectiveness.” Asia Pacific Journal of Tourism Research 12 (3): 245-266. 
Molz, J. G. 2006. “Cosmopolitan Bodies: Fit to Travel and Travelling to Fit.” Body and Society 12 (3): 1-21.

Morgan, M., and F. Xu. 2009. "Student Travel Experiences: Memories and Dreams.” Journal of Hospitality Marketing \& Management 18 (2): 216-236.

Mueller, S., M. Peters, and K. Weiermair. 2009. "Cultural Mobility and Acceptance: The Case of Japanese Tourists in Alpine Destinations." Tourism Analysis 14 (4): 457-470.

Netemeyer, R. G., W. O. Bearden, and S. Sharma. 2003. Scaling Procedures: Issues and Applications. Thousand Oaks, Calif: Sage Publications.

Nowaczek, A., and B. Smale. 2010. "Exploring the Predisposition of Travellers to Qualify as Ecotourists: The Ecotourist Predisposition Scale.” Journal of Ecotourism 9 (1): 4561.

Nunnally, J. C., and I. H. Bernstein. 1994. “The Assessment of Reliability.” Psychometric Theory 3 (1): 248-292.

Prebensen, N. K., and J. Xie. 2017. "Efficacy of Co-Creation and Mastering on Perceived Value and Satisfaction in Tourists' Consumption.” Tourism Management 60:166-176.

Prebensen, N. K., and L. Foss. 2011. "Coping and Co-Creating in Tourist Experiences." International Journal of Tourism Research 13 (1): 54-67.

Prebensen, N. K., J. Vittersø, and T. I. Dahl. 2013. "Value Co-Creation Significance of Tourist Resources." Annals of Tourism Research 42:240-261.

Raymond, E. M., and C. M. Hall. 2008. "The Development of Cross-Cultural (Mis) Understanding Through Volunteer Tourism.” Journal of Sustainable Tourism 16 (5): $530-543$.

Reisinger, Y. 1994. "Tourist-Host Contact as a Part of Cultural Tourism.” World Leisure and Recreation 36 (2): 24-28.

Reisinger, Y. 2009. International Tourism: Cultures and Behavior. Burlington, MA: 
Butterworth-Heinemann.

Richards, G. 2018. “Cultural Tourism: A Review Of Recent Research And Trends.” Journal of Hospitality and Tourism Management 36: 12-21.

Scherle, N., and A. Nonnenmann. 2008. "Swimming in Cultural Flows: Conceptualising Tour Guides as Intercultural Mediators and Cosmopolitans." Journal of Tourism and Cultural Change 6 (2): 120-137.

Sobel, M. E. 1982. “Asymptotic Confidence Intervals for Indirect Effects in Structural Equation Models.” Sociological Methodology 13:290-312.

Su, C. J., A. M. Lebrun, P. Bouchet, J. R. Wang, N. Lorgnier, and J. H. Yang. 2016. “Tourists' Participation and Preference-Related Belief in Co-Creating Value of Experience: A Nature-Based Perspective.” Service Business 10 (4): 823-846.

Su, M. M., Y. Long, G. Wall, and M. Jin. 2016. "Tourist-Community Interactions in Ethnic Tourism: Tuva Villages, Kanas Scenic Area, China.” Journal of Tourism and Cultural Change 14 (1): 1-26.

Swain, M. B. 2009. "The Cosmopolitan Hope of Tourism: Critical Action and Worldmaking Vistas." Tourism Geographies 11 (4): 505-525.

The Central News Agency. 2020. "Leading by the Elder of Tsou Indigenous Tribe to Promote the Mountain Tourism Experience." https://www.cna.com.tw/news/aloc/202008120171.aspx (accessed September 12, 2020).

Thompson, J. A., and J. S. Bunderson. 2001. "Work-Nonwork Conflict and The Phenomenology of Time: Beyond the Balance Metaphor." Work and Occupations 28 (1): $17-39$.

Tsaur, S. H., and J. H. Tu. 2019. "Cultural Competence for Tour Leaders: Scale Development and Validation." Tourism Management 71:9-17. 
Tsaur, S. H., C. H. Yen, and H. Y. Teng. 2018. “Tourist-Resident Conflict: A Scale Development and Empirical Study.” Journal of Destination Marketing and Management 10:152-163.

Tung, V. W. S., and J. B. Ritchie. 2011. "Exploring the Essence of Memorable Tourism Experiences." Annals of Tourism Research 38 (4): 1367-1386.

United Nations World Tourism Organization. 2018. Tourism and Culture Synergies. Madrid: UNWTO.

Urry, J. 1995. Consuming Places. London: Routledge.

Urry, J. 2002. The Tourist Gaze. 2nd ed. London: Sage.

Veasna, S., W. Y. Wu, and C. H. Huang. 2013. “The Impact of Destination Source Credibility on Destination Satisfaction: The Mediating Effects of Destination Attachment and Destination Image.” Tourism Management 36:511-526.

Wang, W., S. T. Cole, and J. S. Chen. 2018. “Tourist Innovation in Air Travel.” Journal of Travel Research 57 (2): 164-177.

Wei, C., W. Zhao, C. Zhang, and K. Huang. 2019. "Psychological Factors Affecting Memorable Tourism Experiences.” Asia Pacific Journal of Tourism Research 24 (7): $619-632$.

Xie, P. F., T. C. Wu, and H. W. Hsieh. 2012. "Tourists' Perception of Authenticity in Indigenous Souvenirs in Taiwan.” Journal of Travel \& Tourism Marketing 29 (5): $485-500$.

Ye, B. H., H. Q. Zhang, and P. P. Yuen. 2013. “Cultural Conflicts or Cultural Cushion?” Annals of Tourism Research 43:321-349.

Yu, J., and T. J. Lee. 2014. “Impact of Tourists’ Intercultural Interactions.” Journal of Travel Research 53 (2): 225-238.

Zhang, H., D. X. Fan, T. S. Tse, and B. King. 2017. "Creating a Scale for Assessing Socially 
Sustainable Tourism." Journal of Sustainable Tourism 25 (1): 61-78.

Zhang, H., Y. Wu, and D. Buhalis. 2018. "A Model of Perceived Image, Memorable Tourism Experiences and Revisit Intention." Journal of Destination Marketing and Management 8:326-336. 
Table 1. Constructs related to tourist intercultural competence applied in the tourism literature

\begin{tabular}{|c|c|c|c|c|c|c|c|}
\hline \multirow{2}{*}{$\begin{array}{l}\text { Author(s) and } \\
\text { publication year }\end{array}$} & \multirow{2}{*}{$\begin{array}{l}\text { Research } \\
\text { methods }\end{array}$} & \multirow{2}{*}{$\begin{array}{l}\text { Research } \\
\text { contexts }\end{array}$} & \multirow{2}{*}{ Relevant concepts } & \multicolumn{4}{|c|}{ Constructs of tourist intercultural competence } \\
\hline & & & & $\begin{array}{l}\text { Intercultural } \\
\text { responsibility }\end{array}$ & $\begin{array}{c}\text { Intercultural } \\
\text { understanding }\end{array}$ & $\begin{array}{l}\text { Intercultural } \\
\text { appreciation }\end{array}$ & $\begin{array}{l}\text { Intercultural } \\
\text { action }\end{array}$ \\
\hline McIntosh (2004) & Qualitative & $\begin{array}{l}\text { Indigenous } \\
\text { tourism }\end{array}$ & Tourists' appreciation & & & $\mathrm{V}$ & $\mathrm{V}$ \\
\hline Molz (2006) & Qualitative & $\begin{array}{l}\text { International } \\
\text { tourism }\end{array}$ & Cosmopolitan tourists & $\mathrm{V}$ & & & \\
\hline $\begin{array}{l}\text { Raymond and } \\
\text { Hall (2008) }\end{array}$ & Qualitative & $\begin{array}{l}\text { Volunteer } \\
\text { tourism }\end{array}$ & Intercultural understanding & & $\mathrm{V}$ & & \\
\hline $\begin{array}{l}\text { Mueller, Peters, } \\
\text { and Weiermair } \\
(2009) .\end{array}$ & Qualitative & $\begin{array}{l}\text { Cultural } \\
\text { tourism }\end{array}$ & Cultural mobility & & & $\mathrm{V}$ & $\mathrm{V}$ \\
\hline Swain (2009) & Qualitative & $\begin{array}{l}\text { International } \\
\text { tourism }\end{array}$ & Cosmopolitan & $\mathrm{V}$ & $\mathrm{V}$ & $\mathrm{V}$ & \\
\hline $\begin{array}{l}\text { Gnoth and Zins } \\
(2010)\end{array}$ & Quantitative & $\begin{array}{l}\text { International } \\
\text { tourism }\end{array}$ & International tourist role & & & $\mathrm{V}$ & $\mathrm{V}$ \\
\hline $\begin{array}{l}\text { Nowaczek and } \\
\text { Smale (2010) }\end{array}$ & Quantitative & Ecotourism & Ecotourist predisposition & V & & $\mathrm{V}$ & $\mathrm{V}$ \\
\hline Donohoe (2011) & Qualitative & Ecotourism & $\begin{array}{l}\text { Culturally sensitive } \\
\text { ecotourism }\end{array}$ & V & & & \\
\hline $\begin{array}{l}\text { Gnoth and Zins } \\
\text { (2013) }\end{array}$ & Quantitative & $\begin{array}{l}\text { Cultural } \\
\text { tourism }\end{array}$ & Tourism cultural contact & & & $\mathrm{V}$ & $\mathrm{V}$ \\
\hline $\begin{array}{l}\text { Ye, Zhang and } \\
\text { Yuen (2013) }\end{array}$ & Quantitative & $\begin{array}{l}\text { International } \\
\text { tourism }\end{array}$ & Intercultural competence & & V & & V \\
\hline $\begin{array}{l}\text { Kirillova, Lehto, } \\
\text { and Cai (2015) }\end{array}$ & Quantitative & $\begin{array}{l}\text { Volunteer } \\
\text { tourism }\end{array}$ & $\begin{array}{l}\text { Intercultural sensitivity, } \\
\text { intercultural understanding }\end{array}$ & $\mathrm{V}$ & V & V & \\
\hline
\end{tabular}




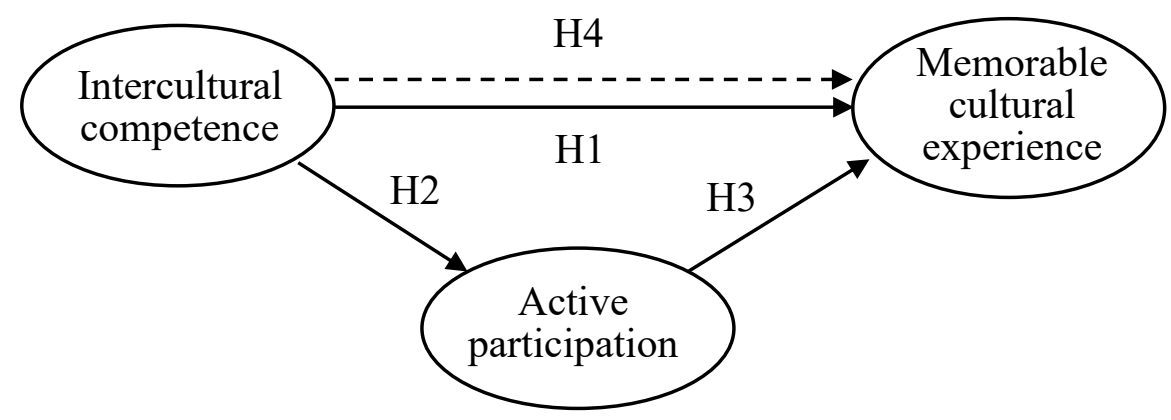

Figure 1. Research model

Note: solid line for direct effect; dotted line for mediating effect. 
Table 2. Item generation

\begin{tabular}{ll}
\hline \multicolumn{1}{c}{ Items } & \multicolumn{1}{c}{ Sources } \\
\hline Intercultural responsibility & Interview \\
I respect a destination's heritage. & Nowaczek \& Smale, 2010 \\
I respect the differences between cultures & Molz, 2006 \\
I tolerate the differences between cultures & Interview \\
I comply with a destination's cultural rules. & Swain, 2009 \\
I'm open-minded when traveling. & Interview \\
When I travel, I'm careful and ask more questions to show & \\
cautious behavior. & Interview \\
I can accept a destination's culture that is different from my own & \\
background. & Interview \\
I will follow the direction of the service persons or tour guides. & \\
Intercultural understanding & Interview \\
I am aware of the differences between cultures. & Interview \\
I compare the differences between cultures. & Interview \\
I try to reflect on my own culture after a cultural experience at a & \\
destination. & Gnoth \& Zins, 2013 \\
I try to see the world through locals' eyes. & Interview \\
I try to learn about cultural advantages. & Lee, Jan, \& Yang, 2013 \\
I try to understand local culture. & \\
Intercultural appreciation & Gnoth \& Zins, 2010 \\
I prefer unique and novel destination cultures. & Gnoth \& Zins, 2010 \\
I like to make contact with a novel culture. & Gnoth \& Zins, 2013 \\
I am interested in the destination's culture. & Interview \\
I can appreciate the beauty of a destination's culture. & Interview \\
I can appreciate destination lifestyle. & \\
Intercultural action & Nowaczek \& Smale, 2010 \\
I enjoy interacting with objects at a destination. & Gnoth \& Zins, 2013 \\
I would like to experience a destination's authentic culture. & Gnoth \& Zins, 2013 \\
I try to learn about the cultural background of a destination. & Interview \\
I reference the cultural information of a destination. & Nowaczek \& Smale, 2010 \\
I enjoy taking part in local activities and cultural exchanges. & Gnoth \& Zins, 2010 \\
I prefer to live the way the people I visit live. & Molz, 2006 \\
I try to blend in with locals. & \\
\hline
\end{tabular}




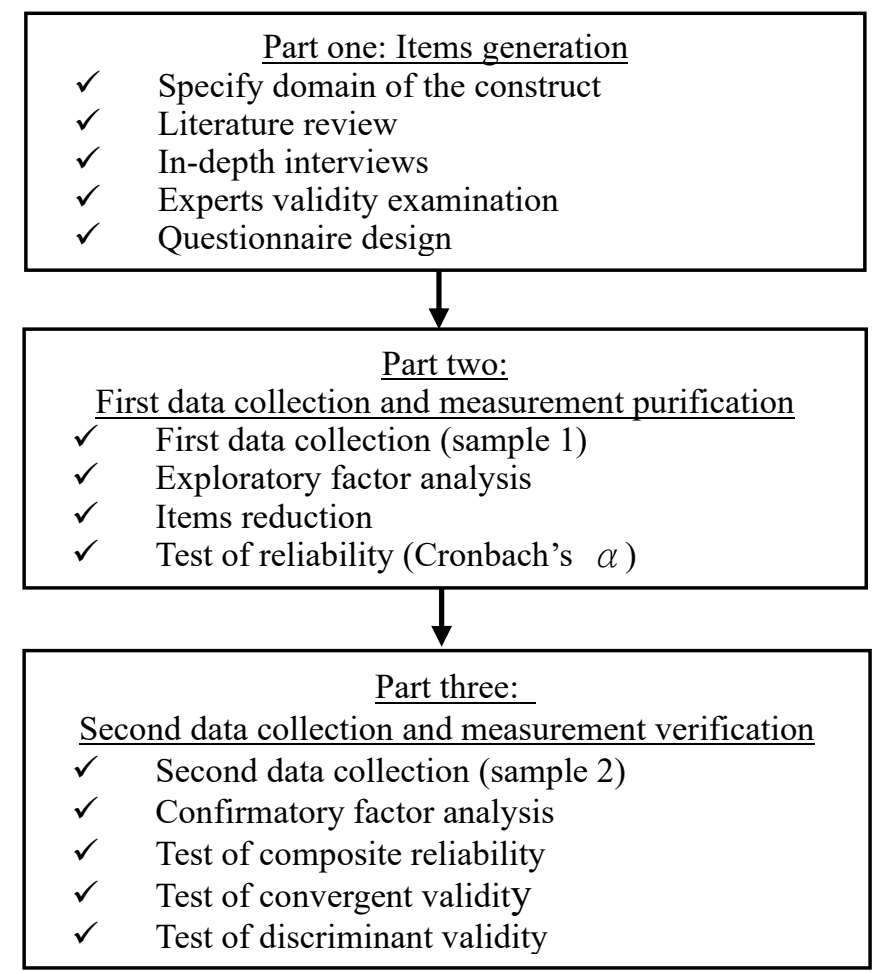

Figure 2. Flowchart of the scale development procedure 
Table 3. Results of the EFA (sample 1, N=341) and CFA (sample 2, $\mathrm{N}=367$ )

\begin{tabular}{|c|c|c|c|c|c|c|c|c|c|c|}
\hline Factors/Items & Mean & $\begin{array}{l}\text { Factor } \\
\text { loading }\end{array}$ & $\begin{array}{l}\text { Eigen- } \\
\text { value }\end{array}$ & $\begin{array}{l}\text { Variance } \\
(\%)\end{array}$ & Cronbach's a & Mean & SFL & t-value & $\mathrm{CR}$ & AVE \\
\hline Factor 1. Intercultural responsibility & 4.41 & & 7.610 & 17.620 & 0.849 & 4.20 & & & 0.875 & 0.539 \\
\hline I respect a destination's heritage. & 4.54 & 0.784 & & & & 4.27 & 0.83 & 18.78 & & \\
\hline I respect and tolerate cultural differences. & 4.52 & 0.766 & & & & 4.25 & 0.80 & 17.92 & & \\
\hline I comply with a destination's cultural rules. & 4.40 & 0.693 & & & & 4.18 & 0.70 & 14.70 & & \\
\hline I'm open-minded when traveling. & 4.44 & 0.692 & & & & 4.24 & 0.72 & 15.34 & & \\
\hline $\begin{array}{l}\text { When I travel, I'm careful and ask more questions to } \\
\text { show cautious behavior. }\end{array}$ & 4.28 & 0.671 & & & & 4.19 & 0.68 & 14.20 & & \\
\hline $\begin{array}{l}\text { I can accept a destination's culture that is different } \\
\text { from my own background. }\end{array}$ & 4.28 & 0.584 & & & & 4.09 & 0.66 & 13.64 & & \\
\hline Factor 2. Intercultural understanding & 3.92 & & 1.445 & 12.941 & 0.775 & 3.89 & & & 0.827 & 0.490 \\
\hline I am aware of the differences between cultures. & 4.01 & 0.766 & & & & 3.86 & 0.71 & 14.85 & & \\
\hline I compare the differences between cultures. & 3.92 & 0.762 & & & & 3.89 & 0.72 & 15.07 & & \\
\hline $\begin{array}{l}\text { I try to reflect on my own culture after a cultural } \\
\text { experience at a destination. }\end{array}$ & 3.82 & 0.752 & & & & 3.87 & 0.60 & 11.48 & & \\
\hline I try to see the world through locals' eyes. & 3.82 & 0.535 & & & & 3.81 & 0.74 & 15.58 & & \\
\hline I try to learn about cultural advantages. & 4.03 & 0.458 & & & & 4.03 & 0.72 & 15.18 & & \\
\hline Factor 3. Intercultural appreciation & 4.33 & & 1.767 & 13.473 & 0.819 & 4.15 & & & 0.888 & 0.616 \\
\hline I prefer unique and novel destination cultures. & 4.42 & 0.723 & & & & 4.22 & 0.82 & 18.49 & & \\
\hline I like to make contact with a novel culture. & 4.37 & 0.722 & & & & 4.15 & 0.82 & 18.56 & & \\
\hline I am interested in the destination's culture. & 4.31 & 0.667 & & & & 4.11 & 0.74 & 15.83 & & \\
\hline I can appreciate the beauty of a destination's culture. & 4.29 & 0.604 & & & & 4.13 & 0.78 & 17.08 & & \\
\hline I can appreciate destination lifestyle. & 4.24 & 0.585 & & & & 4.16 & 0.76 & 16.61 & & \\
\hline Factor 4. Intercultural action & 3.97 & & 1.108 & 12.770 & 0.774 & 3.95 & & & 0.833 & 0.501 \\
\hline I would like to interact with objects at a destination. & 3.77 & 0.703 & & & & 3.86 & 0.62 & 12.38 & & \\
\hline $\begin{array}{l}\text { I would like to experience a destination's authentic } \\
\text { culture. }\end{array}$ & 4.16 & 0.682 & & & & 4.00 & 0.76 & 16.27 & & \\
\hline $\begin{array}{l}\text { I try to learn about the cultural background of a } \\
\text { destination. }\end{array}$ & 3.84 & 0.671 & & & & 3.97 & 0.75 & 15.87 & & \\
\hline I reference the cultural information of a destination. & 3.86 & 0.618 & & & & 3.99 & 0.68 & 13.87 & & \\
\hline $\begin{array}{l}\text { I would like to take part in local activities and cultural } \\
\text { exchanges. }\end{array}$ & 4.20 & 0.537 & & & & 3.93 & 0.72 & 15.05 & & \\
\hline
\end{tabular}

Notes. SFL: standard factor loading; CR: composite reliability; AVE: average variance extracted. 
Table 4. Square Roots of the AVE and Correlations between the Latent Factors

Intercultural Intercultural Intercultural Intercultural

responsibility understanding appreciation action

\begin{tabular}{lllll}
\hline Intercultural responsibility & 0.73 & & & \\
Intercultural understanding & $0.59^{* *}$ & 0.70 & & \\
Intercultural appreciation & $0.68^{* *}$ & $0.61 * *$ & 0.79 & \\
Intercultural action & $0.64 * *$ & $0.68 * *$ & $0.59 * *$ & 0.71 \\
\hline
\end{tabular}

Note: $*=p<0.05, * *=p<0.01$. 


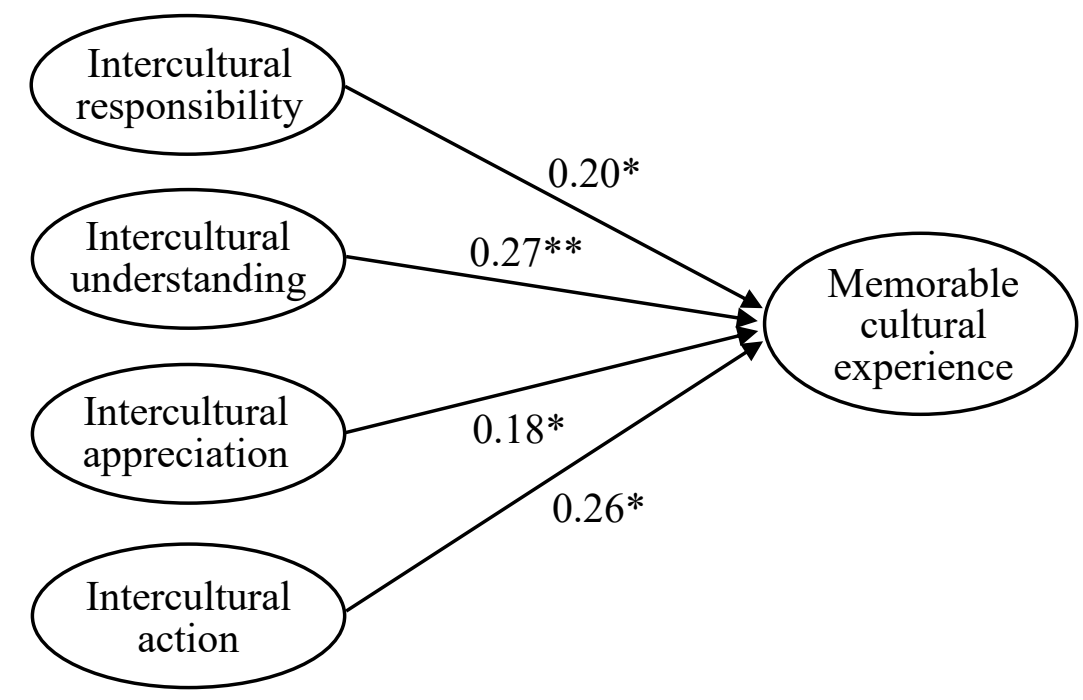

Figure 3. Structural results of the direct model

Note: $*=\mathrm{p}<0.05, * *=\mathrm{p}<0.01$ 


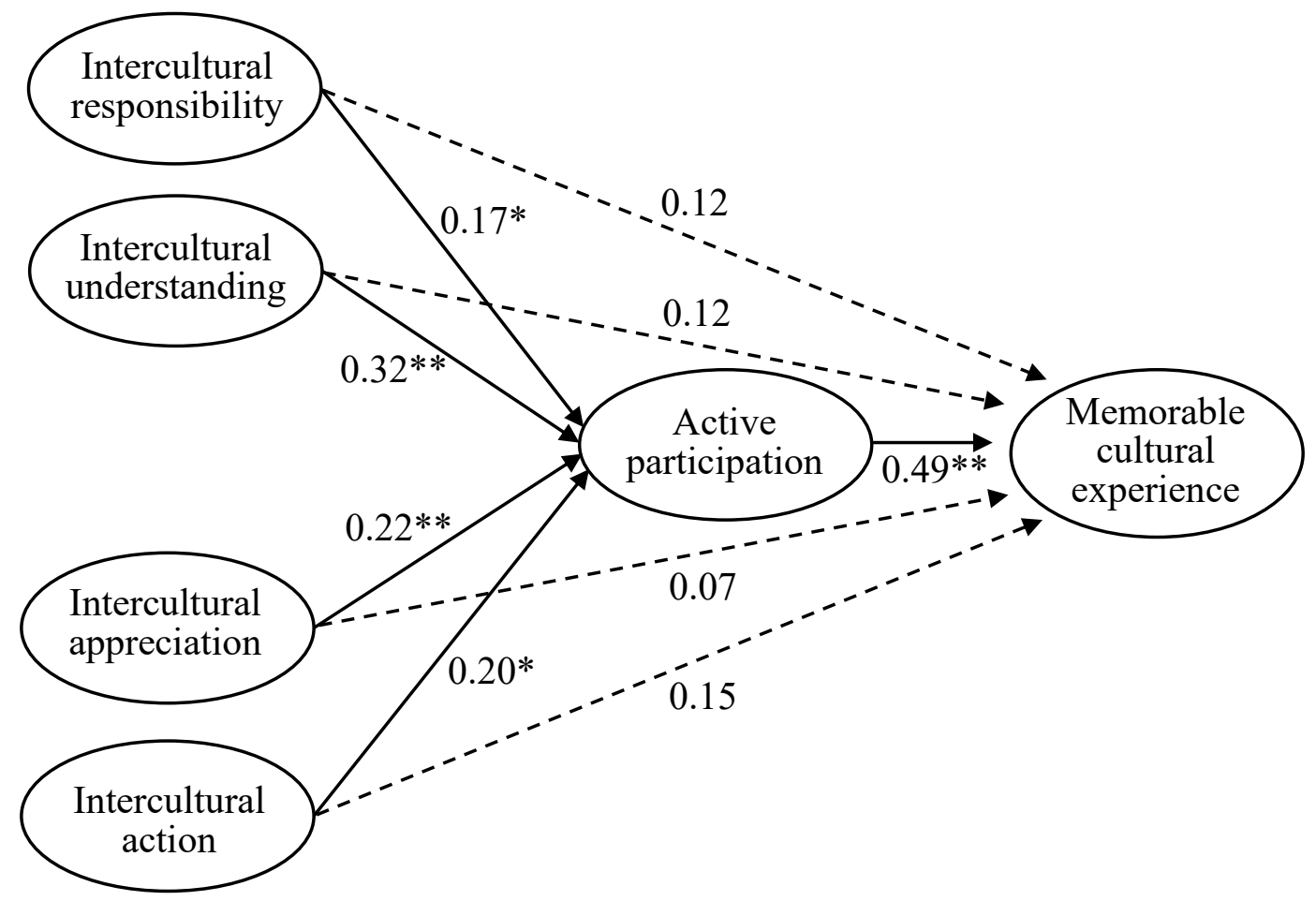

Figure 4. Structural results of mediation model Note: $*=p<0.05, * *=p<0.01$. 
Table 5. Mediation Effect Results

\begin{tabular}{lllll}
\hline Mediating effect & & z-test & $p$ \\
\hline Intercultural responsibility & $\beta=0.09(\mathrm{a}=0.17 \times \mathrm{b}=0.50) ; \mathrm{SE}_{\mathrm{a}}=0.08 ; \mathrm{SE}_{\mathrm{b}}=0.09$ & $1.99^{*}$ & $<0.05$ \\
\hline Intercultural understanding & $\beta=0.16(\mathrm{a}=0.32 \times \mathrm{b}=0.50) ; \mathrm{SE}_{\mathrm{a}}=0.10 ; \mathrm{SE}_{\mathrm{b}}=0.09$ & $2.77^{* *}$ & $<0.01$ \\
\hline Intercultural appreciation & $\beta=0.11(\mathrm{a}=0.22 \times \mathrm{b}=0.50) ; \mathrm{SE}_{\mathrm{a}}=0.08 ; \mathrm{SE}_{\mathrm{b}}=0.09$ & $2.47^{*}$ & $<0.05$ \\
\hline Intercultural action & $\beta=0.10(\mathrm{a}=0.20 \times \mathrm{b}=0.50) ; \mathrm{SE}_{\mathrm{a}}=0.10 ; \mathrm{SE}_{\mathrm{b}}=0.09$ & 1.88 & $>0.05$ \\
\hline
\end{tabular}

Note: Mediating effects were tested using a z-test, with scores calculated using Sobel's (1982) approach: $\mathrm{z}$-value $=\mathrm{a}^{*} \mathrm{~b} / \mathrm{SQRT}\left(\mathrm{b}^{2 *} \mathrm{SE}_{\mathrm{a}}^{2}+\mathrm{a}^{2 *} \mathrm{SE}_{\mathrm{b}}{ }^{2}\right)$; Where a denotes the regression coefficient for the relation between the independent and the mediator variables; $b$ denotes the regression coefficient for the relation between the mediator and the dependent variables; $\mathrm{SE}_{\mathrm{a}}$ denotes the standard error of the relationship between the independent and the mediator variables, and $\mathrm{SE}_{\mathrm{b}}$ denotes the standard error of the relationship between the mediator and the dependent variables. ${ }^{*}=p<0.05,{ }^{* *}=p<0.01$ 